NASA/TM-2003-212032

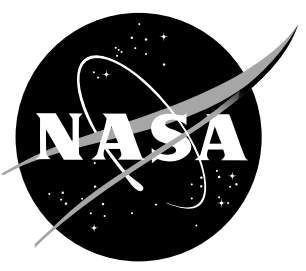

\title{
Modeling Aircraft Wing Loads from Flight Data Using Neural Networks
}

Michael J. Allen and Ryan P. Dibley

NASA Dryden Flight Research Center

Edwards, California 


\section{The NASA STI Program Office...in Profile}

Since its founding, NASA has been dedicated to the advancement of aeronautics and space science. The NASA Scientific and Technical Information (STI) Program Office plays a key part in helping NASA maintain this important role.

The NASA STI Program Office is operated by Langley Research Center, the lead center for NASA's scientific and technical information. The NASA STI Program Office provides access to the NASA STI Database, the largest collection of aeronautical and space science STI in the world. The Program Office is also NASA's institutional mechanism for disseminating the results of its research and development activities. These results are published by NASA in the NASA STI Report Series, which includes the following report types:

- TECHNICAL PUBLICATION. Reports of completed research or a major significant phase of research that present the results of NASA programs and include extensive data or theoretical analysis. Includes compilations of significant scientific and technical data and information deemed to be of continuing reference value. NASA's counterpart of peer-reviewed formal professional papers but has less stringent limitations on manuscript length and extent of graphic presentations.

- $\quad$ TECHNICAL MEMORANDUM. Scientific and technical findings that are preliminary or of specialized interest, e.g., quick release reports, working papers, and bibliographies that contain minimal annotation. Does not contain extensive analysis.

- CONTRACTOR REPORT. Scientific and technical findings by NASA-sponsored contractors and grantees.
- CONFERENCE PUBLICATION.

Collected papers from scientific and technical conferences, symposia, seminars, or other meetings sponsored or cosponsored by NASA.

- SPECIAL PUBLICATION. Scientific, technical, or historical information from NASA programs, projects, and mission, often concerned with subjects having substantial public interest.

- TECHNICAL TRANSLATION. Englishlanguage translations of foreign scientific and technical material pertinent to NASA's mission.

Specialized services that complement the STI Program Office's diverse offerings include creating custom thesauri, building customized databases, organizing and publishing research results...even providing videos.

For more information about the NASA STI Program Office, see the following:

- Access the NASA STI Program Home Page at http://www.sti.nasa.gov

- E-mail your question via the Internet to help@sti.nasa.gov

- Fax your question to the NASA Access Help Desk at (301) 621-0134

- Telephone the NASA Access Help Desk at (301) 621-0390

- Write to:

NASA Access Help Desk

NASA Center for AeroSpace Information 7121 Standard Drive

Hanover, MD 21076-1320 


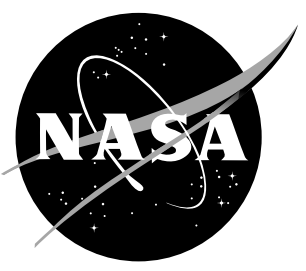

\section{Modeling Aircraft Wing Loads from Flight Data Using Neural Networks}

Michael J. Allen and Ryan P. Dibley

NASA Dryden Flight Research Center

Edwards, California

National Aeronautics and

Space Administration

Dryden Flight Research Center

Edwards, California 93523-0273 


\section{NOTICE}

Use of trade names or names of manufacturers in this document does not constitute an official endorsement of such products or manufacturers, either expressed or implied, by the National Aeronautics and Space Administration.

Available from the following:

NASA Center for AeroSpace Information (CASI)

7121 Standard Drive

Hanover, MD 21076-1320

(301) 621-0390
National Technical Information Service (NTIS) 5285 Port Royal Road Springfield, VA 22161-2171

(703) $487-4650$ 


\begin{abstract}
Neural networks were used to model wing bending-moment loads, torsion loads, and control surface hinge-moments of the Active Aeroelastic Wing (AAW) aircraft. Accurate loads models are required for the development of control laws designed to increase roll performance through wing twist while not exceeding load limits. Inputs to the model include aircraft rates, accelerations, and control surface positions. Neural networks were chosen to model aircraft loads because they can account for uncharacterized nonlinear effects while retaining the capability to generalize. The accuracy of the neural network models was improved by first developing linear loads models to use as starting points for network training. Neural networks were then trained with flight data for rolls, loaded reversals, wind-up-turns, and individual control surface doublets for load excitation. Generalization was improved by using gain weighting and early stopping. Results are presented for neural network loads models of four wing loads and four control surface hinge moments at Mach 0.90 and an altitude of 15,000 ft. An average model prediction error reduction of 18.6 percent was calculated for the neural network models when compared to the linear models. This paper documents the input data conditioning, input parameter selection, structure, training, and validation of the neural network models.
\end{abstract}

\title{
NOMENCLATURE
}

AAW Active Aeroelastic Wing

AFTI advanced fighter technology integration

$E_{R M S} \quad$ RMS error

$g \quad$ acceleration of gravity

LEF leading-edge flap

MLC maneuver load control

$n \quad$ number of samples

OBES onboard excitation system

$P \quad$ measured load

RMS root mean square

SRA systems research aircraft

TEF trailing-edge flap

$x \quad$ input to node

$y \quad$ estimated load

$z \quad$ output of node 


\section{INTRODUCTION}

Nearly one hundred years ago, the Wright brothers amazed the world with the invention of the first practical airplane. One of the enabling technologies for this feat was the ability of the pilot to control the aircraft in pitch, yaw, and roll. Whereas pitch and yaw control was accomplished with movable surfaces, roll control was accomplished by warping the wings. After this airplane, few, if any, aircraft have used wing warping for roll control. Instead, fixed control surfaces called ailerons are attached to a more rigid wing and moved differentially to produce rolling moments.

One problem associated with the use of ailerons is the reduction or reversal of control effectiveness in roll when flying at high dynamic pressure. Normal aileron effectiveness depends upon the ability to change wing lift by changing wing camber. Deflection of an aileron control surface when flying at high dynamic pressure has two effects. The first effect is a change in lift caused by a change in wing camber. This paper will refer to this effect as normal aileron operation. The second effect, referred to as adverse wing twist in this paper, is a change in lift as a result of wing twist caused by aileron deflection. This effect acts to oppose normal aileron operation and can cause reduced or reversed lateral control (aileron reversal). Common methods used to overcome adverse wing twist include increasing the torsional stiffness of the wing, using spoilers or differential tail for roll control, and using inboard ailerons for high speed roll control. Reference 1 contains a general explanation and history of adverse wing twist.

Fighter aircraft are susceptible to adverse wing twist because they are required to provide high maximum roll rate performance at high dynamic pressure flight conditions. This requirement usually leads to the use of differential tail deflections for roll control and stiffer, heavier wings to retain aileron effectiveness at high dynamic pressure. Initial flight testing of the F/A-18 airplane at flight conditions of Mach 0.7 at sea level revealed problems with aileron reversal. ${ }^{2}$ The problem was remedied by changing the flight control laws and by adding structure to the wing; however, performance measures such as range, payload, and landing distance suffered as a result of the additional wing weight.

A flight research program using a modified F/A-18 airplane, shown in Figure 1, was begun at NASA Dryden Flight Research Center (Edwards, California) to improve understanding of the aeroelastic effects of reduced stiffness fighter wings at high dynamic pressure and to use that knowledge to improve

maneuverability using wing twist for roll control. ${ }^{3}$ The first phase of the Active Aeroelastic Wing (AAW) project identified aerodynamic, aeroelastic, and loads information for use in simulation and control design. Models of AAW wing loads are critical to the success of the AAW project because future flight phases with new control laws will move the surfaces in unconventional ways and must not exceed the load limits of the wing. This paper describes methods used to derive accurate loads models. 


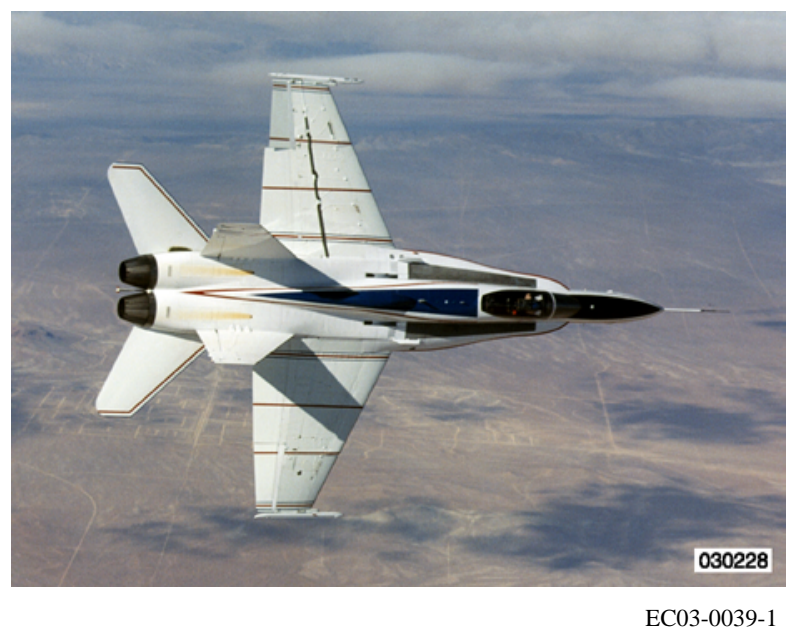

Figure 1. AAW airplane.

Flight tests with the AAW airplane were conducted to gather data to produce loads models. Several methods can use this data to generate loads models. One method is to use linear regression to model the relationship of aircraft states and control surface positions to wing loads. A limitation with this method is that linear regression cannot easily accommodate nonlinear relationships between the input variables and the loads. Nonlinear regression has been used to model nonlinear relationships but generally requires selection of a nonlinear mapping function. ${ }^{4}$ One method of accomplishing nonlinear regression without a priori knowledge of the shape of the nonlinearity is to use a neural network. A neural network method was chosen to develop loads models for the AAW aircraft because nonlinear effects were expected to occur.

Previous projects have been successful in using loads models for a variety of purposes. Accurate loads models were required for the advanced fighter technology integration (AFTI) F-111 aircraft maneuver load control (MLC) experiment. ${ }^{5}$ In the MLC application, wing load models were required by the MLC algorithms to alleviate loads. More recently, flight data were used to determine loads models for the F/A-18 systems research aircraft (SRA) at NASA Dryden Flight Research Center. ${ }^{6}$ In the SRA study, flight data were used to create a linear loads model for the left outboard leading-edge-flap (LEF) hinge moment at several flight conditions. Stepwise linear regression was used to calculate the coefficients of the loads models. This process proved to be very effective in modeling hinge moment, but validation testing with independent maneuvers was not performed. Flight data from this study revealed inaccuracies in the analytical preflight predictions of as much as 130 percent.

Haas, Flitter, Milano, and Imber used a more complete approach to loads model derivation to model component loads of a helicopter rotor system. ${ }^{7-9}$ Both linear regression and neural networks were used to create loads models. Nonlinear effects were found in the data and accounted for either by using linear models with derived parameters created by nonlinear mapping functions or by using neural network models. The neural network loads models did not require the use of derived parameters. Both methods worked well in the helicopter application. Comparison of neural network models with basic parameters to the linear regression model with derived parameters revealed that the neural network models could 
replicate validation data with 4 percent lower root-mean-square (RMS) error for the blade bending moment and 30 percent lower RMS error for the pushrod load. ${ }^{9}$ When nonlinear functions and derived parameters were not used in the linear method, the accuracy of the linear model suffered and the neural network had an average 26 percent lower RMS error on validation data. Haas, et. al., concluded that using both linear regression and neural networks to create loads models gives the researcher a better understanding of the problem and a higher confidence in the resulting model.

The forementioned work benefited the development of the AAW loads model in many ways. Both linear and neural network models were used to model AAW wing loads, and similar methods were used to validate the resulting models. The work presented here differs in that this study used different methods to train the neural networks and that the modeled system is a fixed wing airplane at transonic flight condition. Nonlinearities because of transonic flow presented a unique modeling problem. Olney, et. al., performed work on a similar aircraft and flight condition but only included the outboard leading-edge-flap hinge moment and only used linear methods. ${ }^{6}$ The work presented in this study takes advantage of three techniques to improve the neural network's ability to predict new data or generalize: The use of a previously created linear model as a starting point for the neural network; neural network gain weighting; and separate validation data to halt training before generalization is degraded (early stopping). This paper describes the inputs, outputs, structure, design, and analysis of a set of AAW neural network loads models.

\section{FLIGHT TEST DATA}

Each wing of the AAW aircraft was instrumented with approximately 100 strain gage bridges. These strain gages determine the hinge moments of each of the four control surfaces as well as the bending moment and torque loads at the wing-root and wing-fold positions. Figure 2 shows the wing-load measurement locations. Extensive ground tests were conducted to calibrate the output of the strain gages. ${ }^{10}$ During these tests, the wing was covered with 52 load pads divided into 16 load zones that covered 60 percent of the lower wing surface.

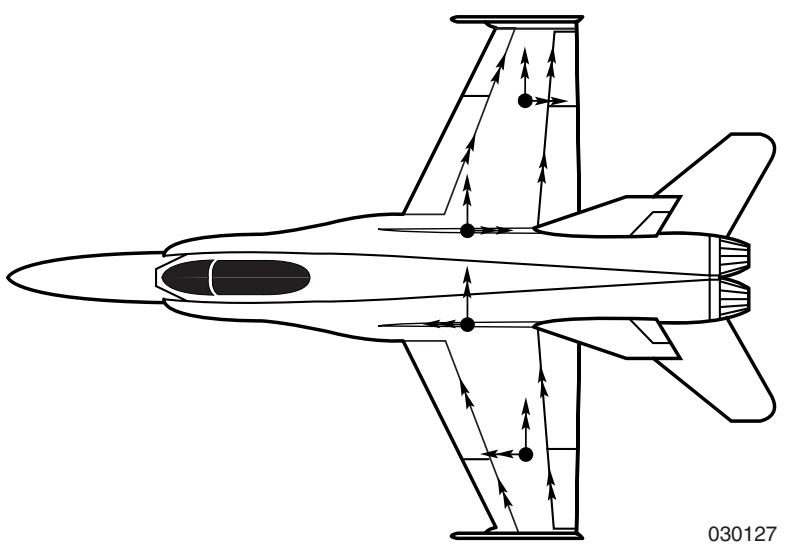

Figure 2. Locations of AAW measured loads. 
Each wing was subjected to a wide range of distributed and point loads, and the strain gage outputs were measured. The measured load values and the gage outputs were used to develop equations to calculate wing loads from strain gage output. Linear regression was used to generate the loads equations. ${ }^{4}$ These equations were later used to determine the wing loads during flight. Reference 10 contains details of the AAW loads ground test.

After calibration, extensive flight testing of the AAW airplane was conducted in the fall of 2002 and the spring of 2003 to quantify wing aeroelastic effects, perform airdata calibration, investigate failure scenarios, and gather data needed for aerodynamic and loads models. Preprogrammed onboard excitation system (OBES) maneuvers were used to excite the aircraft response. These maneuvers consisted of a sequence of symmetric or asymmetric doublets designed to excite each surface individually. Figure 3 shows a large collective OBES maneuver. Surface commands generated by the maneuvers are summed with the commands generated by the F/A-18 control system before being sent to the surfaces. Small and medium OBES maneuvers followed the same structure as the large maneuvers but were reduced in magnitude.

Since the OBES maneuvers were small in magnitude, additional piloted maneuvers were flown to identify loads characteristics at higher loads levels. These high load maneuvers consisted of $5 g$ windup turns, $4 \mathrm{~g}$ loaded reversals, and 1/2, 3/4, and full-stick rolls. Pitchup-pushover maneuvers designed for noseboom calibration were also used. All maneuvers described in this paper were flown at Mach 0.90 and an altitude of $15,000 \mathrm{ft}$.

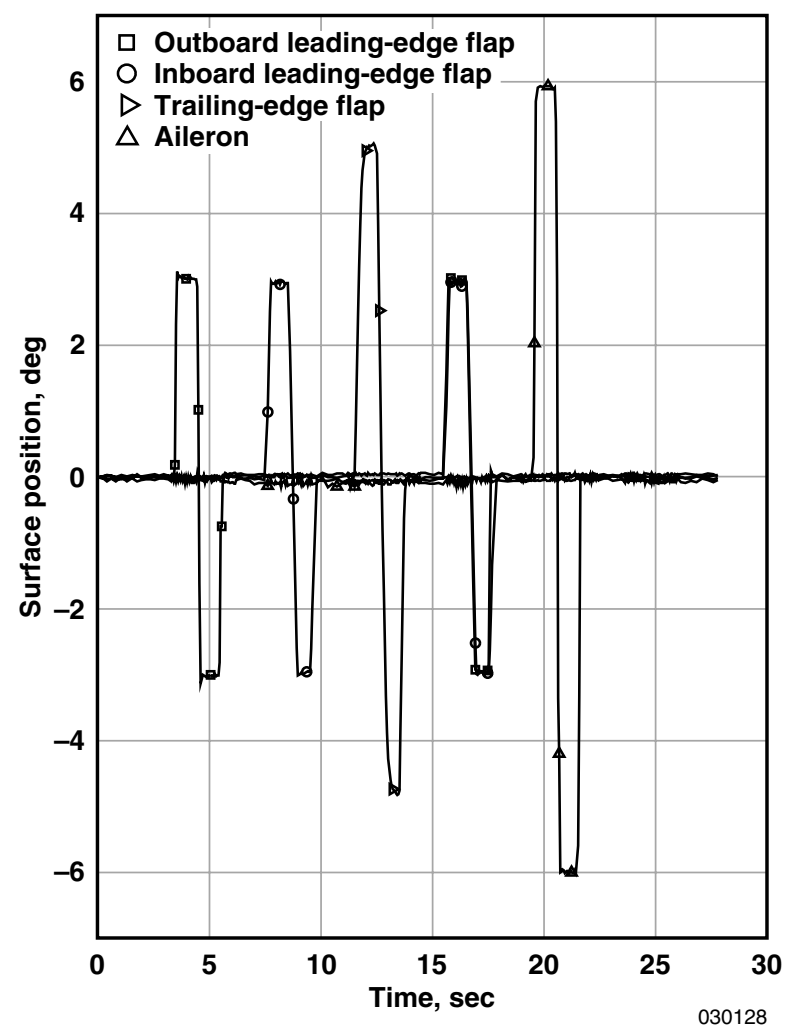

Figure 3. Large collective OBES maneuver. Stabilator position not shown. 


\section{Data Conditioning}

The flight data underwent many data conditioning steps before they were used to create loads models. These steps began by filling in data dropouts and missing data points using linear interpolation. The data were then synchronized in time using measured time tags from the airplane. Data spikes were then removed with an interactive spike removal tool, and the data were filtered with 5th-order low-pass Butterworth filters. The user interactively selected filter cutoff frequencies using time-history and frequency-domain plots. The filters were run forward and backward to minimize filter-induced phase lag. After filtering, the data were resampled at the sample rate of the surface positions using linear interpolation. The next step removed any data points that were added by interpolation during the previous steps. This removal was possible because the loads models are static. High emphasis was placed on data conditioning because of concern that data spikes, noisy data, or invalid data could cause the neural network to train to these anomalies and thereby hinder the ability of the neural network to generalize.

After the invalid data points were removed, each input parameter was scaled using preset scale factors. Scale factors were chosen from simulation data to normalize the inputs to an approximate range of \pm 1.0 to make linear model coefficients more meaningful. Using scaled parameters, the importance of an input in the linear model can be judged by the value of its corresponding model coefficient. Analysis with linear models was used to select inputs for the neural network models.

After scaling, additional data files were created by treating the left and right wing loads separately. Separate left and right data files were created to allow the use of measured left and right loads together during model development. Assuming symmetry, both left and right wing loads can be used to derive the same equation. This derivation was accomplished by reversing the sign on the lateral/directional states and differential surface positions in the left wing files. This method made the left wing loads appear to be right wing loads, and allowed measurements on the left and right wings to be used together.

Specific sections of data were then resampled at a lower sample rate to adjust data density at times during each maneuver when the load was low or the airplane was near trim. By reducing the number of data points at low loads, high load data was given more priority by the model training algorithms. This study used this method of emphasizing high load data points rather than weighted multiple regression ${ }^{8}$ because the data reduction method can be used to benefit linear regression as well as neural network training and this method allows the user more control to choose the relative importance of the data.

\section{Input Parameter Selection}

Table 1 shows the parameters used to develop loads models. These parameters were chosen by first starting with a small set of parameters based on previous work. ${ }^{6,7}$ The set of parameters was then increased by evaluating the benefit of adding new parameters. If a parameter was highly correlated with another parameter, such as angle of attack and normal acceleration, only one was chosen if possible. The final step to remove insensitive parameters was an exhaustive search to remove the least important variables. These techniques were used during linear regression analysis and proved to be an important tool for the selection of input parameters used in the neural network models. 
Table 1. Model input parameters.

\begin{tabular}{|c|c|c|c|c|c|c|c|c|}
\hline Parameter & 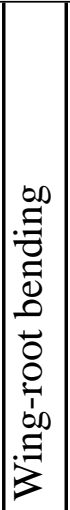 & 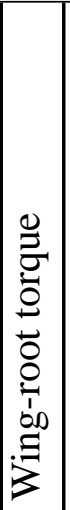 & 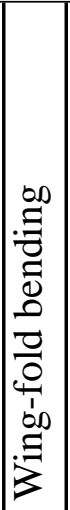 & 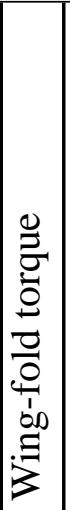 & 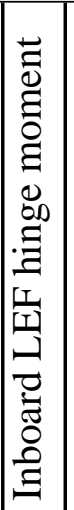 & 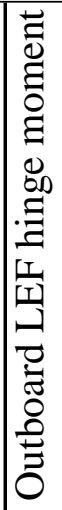 & 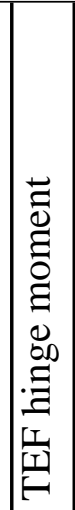 & 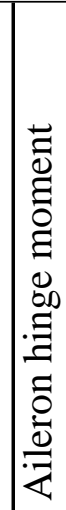 \\
\hline Angle of attack & & & & $\mathrm{X}$ & $\mathrm{X}$ & $\mathrm{X}$ & $\mathrm{X}$ & $\bar{X}$ \\
\hline Angle of sideslip & $\mathrm{X}$ & & $\mathrm{X}$ & & & & & \\
\hline Roll rate & $\mathrm{X}$ & $x$ & $\mathrm{X}$ & $x$ & $\mathrm{X}$ & $X$ & $\mathrm{X}$ & $\mathrm{X}$ \\
\hline Roll acceleration & $\mathrm{X}$ & $\mathrm{X}$ & $X$ & & & & & \\
\hline Normal acceleration & & $\mathrm{X}$ & $\mathrm{X}$ & $\mathrm{X}$ & & & $\mathrm{X}$ & \\
\hline Normal acceleration times fuselage weight & $\mathrm{X}$ & $\mathrm{X}$ & $\mathrm{X}$ & & & & & \\
\hline Inboard leading-edge-flap position & & $\mathrm{X}$ & & & $\mathrm{X}$ & $\mathrm{X}$ & & \\
\hline Outboard leading-edge-flap position & & $\mathrm{X}$ & & $\mathrm{X}$ & & $\mathrm{X}$ & & \\
\hline Trailing-edge-flap position & & $\mathrm{X}$ & & $\mathrm{X}$ & & & $\mathrm{X}$ & $\mathrm{X}$ \\
\hline Aileron position & & $\mathrm{X}$ & & $\mathrm{X}$ & & $\mathrm{X}$ & $\mathrm{X}$ & $x$ \\
\hline Collective aileron & $\mathrm{X}$ & & $\mathrm{X}$ & & & & & \\
\hline Differential aileron & $\mathrm{X}$ & & $\mathrm{X}$ & & & & & \\
\hline Collective trailing-edge-flap & $\mathrm{X}$ & & & & & & & \\
\hline Differential trailing-edge-flap & $\mathrm{X}$ & & $\mathrm{X}$ & & & & & \\
\hline Collective stabilator & $\mathrm{X}$ & & $\mathrm{X}$ & & & & & \\
\hline
\end{tabular}

NEURAL NETWORK STRUCTURE

A neural network is a network of fixed functions with variable gains and biases. Gains and biases of the neural network were iteratively adjusted to produce a desired model. This study used single hidden-layer feed-forward networks. This type of network consists of an input layer, a single hidden layer, and an output layer. Figure 4 is a partial depiction of a typical single hidden-layer neural network. The two inputs to this neural network, angle of attack and roll rate, are weighted and sent to two nonlinear functions or nodes in the single hidden layer. The output is simply a linear combination of a bias and the outputs from the nodes in the hidden layer. 


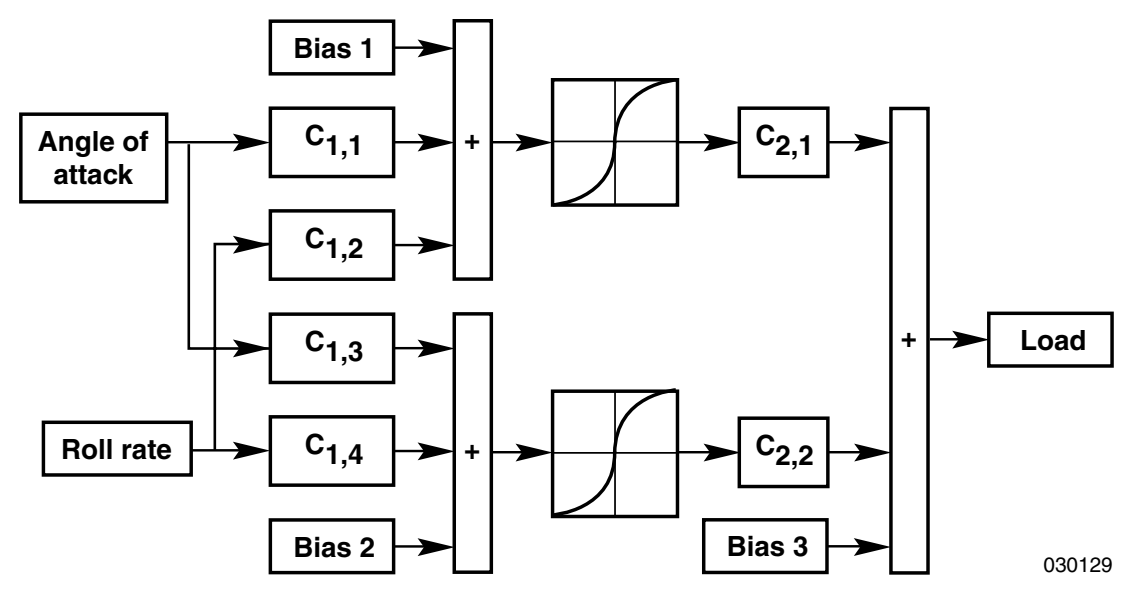

Figure 4. Typical single hidden-layer neural network with two inputs.

Neural network size was determined through parametric studies. During these studies, separate training maneuvers and validation maneuvers were identified and used. In this way, the performance of a model that was created with training maneuvers could be evaluated with the validation maneuvers. The next section discusses selection of training and validation maneuvers. Performance was determined by comparing RMS errors $\left(E_{R M S}\right)$ from equation (1):

$$
E_{R M S}=\frac{\sqrt{\frac{\sum_{i=1}^{n}(P-y)^{2}}{n}}}{\text { load limit }}
$$

where $n$ is the number of samples in a particular maneuver, $P$ is the measured load, and $y$ is the estimated load. This study used load limits taken from design limit load specifications and previous flight test results.

Parametric studies with single and double hidden-layer neural networks of various sizes showed no significant improvement with using multiple hidden layers. Initial studies conducted using back propagation training with the Levenberg-Marquardt optimization ${ }^{11}$ and no gain weighting or early stopping resulted in neural networks with five nodes in a single hidden layer having the best performance. Additional nodes resulted in over-fitting. Further studies with Bayesian regulation ${ }^{12}$ were conducted to determine the minimum number of nodes required to fit the data. Figure 5 shows the normalized average RMS error as a function of neural network size for the wing-root and wing-fold bending moment and torque loads for six validation maneuvers. Eight-node neural networks were selected for these loads. The study with surface hinge moments shown in figure 6 resulted in the decision to use eight-node neural networks for the leading-edge-flap hinge moment models and five-node neural networks for the aileron hinge moment models. Neural networks with six nodes were used for the outboard leading-edge-flap hinge moment and inboard trailing-edge-flap hinge moment models. 


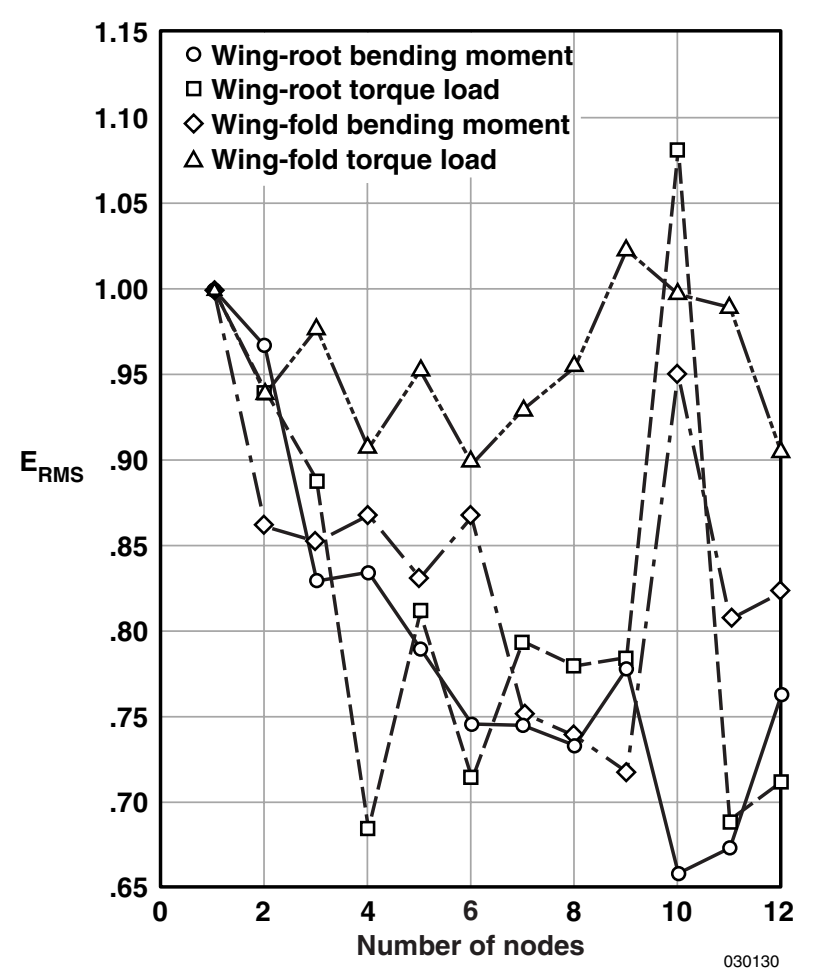

Figure 5. Effect of neural network size on RMS error for wing bending and torque loads.

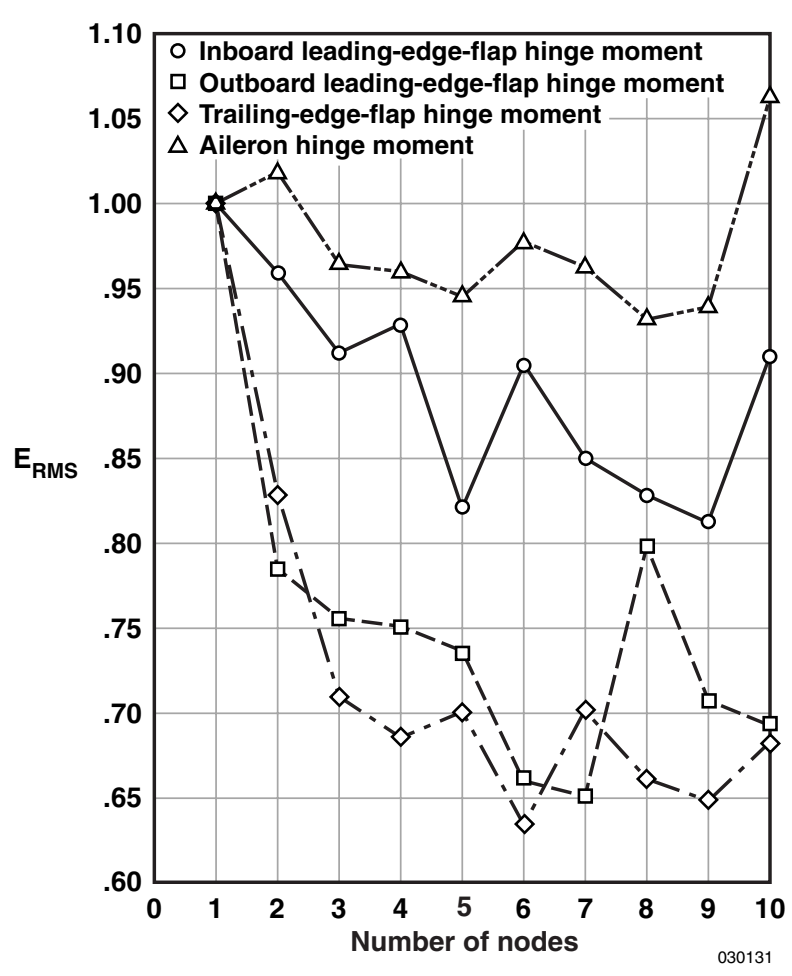

Figure 6. Effect of neural network size on RMS error for surface hinge moments.

The function chosen for the hidden-layer nodes is an approximated hyperbolic tangent shape given by equation (2): ${ }^{13}$

$$
Z=\frac{2}{\left(1+e^{(-2 x)}\right)-1}
$$

where $Z$ is the output of the node with input $x$.

The output of these nodes is summed along with a bias term to give the model output load.

\section{NEURAL NETWORK TRAINING}

Linear loads models were used to initialize the neural network models. Initialization was accomplished by training the neural network with data generated from a linear model that was given a series of random inputs. This training is similar in result to the work done by Ferrari and Stengel, where a set of linear systems was used to analytically create a nonlinear neural network system. ${ }^{14}$ This study did not employ this technique because the required choice of set operating points was not straightforward for this system. The method of using linear models to initialize the neural network models improved model accuracy and reduced the number of neural network training iterations on the flight data required for convergence. 
Back propagation with Levenberg-Marquardt optimization was selected for this study. To improve generalization, neural network gain weighting was used. Bayesian regulation was used to determine the ratio of neural network gain weighting to error weighting. Despite these measures to improve generalization, over-training was still possible because the amount of training data in nonlinear regions was not always sufficient. For this reason, early stopping was used during training. Early stopping uses separate validation data to halt neural network training when additional training cycles no longer improve the accuracy of the model. This technique limited the number of training cycles to approximately 40.

Validation data consisted of entire maneuvers that were not used to train the neural network. These maneuvers were carefully chosen to represent the maneuvers flown but not be larger in magnitude than the training maneuvers. For this study, training maneuvers consisted of small, medium, and large individual surface doublets (OBES maneuvers); a windup turn, a pitchup pushover; a 1/2-stick roll; a full-stick roll; and a full-stick loaded reversal. Validation maneuvers consisted of repeated OBES maneuvers, a 3/4-stick roll, a 2/3-stick roll, a 1/2-stick loaded reversal, and a small pitchup pushover.

Occasionally during training, early stopping halted neural network training prematurely because the limited set of validation data did not include enough information to reflect improvements made to the training data. To remedy this, validation data used in the early stopping algorithm was augmented with a limited amount of randomly selected data points taken from the training set. The augmented validation data set effectively prolonged training until the fit of the model to both validation and training data no longer improved. The use of augmented data sometimes allowed the training algorithm to depart from a local minimum to find a better solution.

\section{RESULTS}

The neural network models were able to identify and fit many nonlinear trends in the flight data. These trends include buffet, nonlinear surface effectiveness, and nonlinear loading with angle of attack and roll rate. Buffet is unsteady flow separation found at transonic Mach numbers and increased angle of attack. Buffet occasionally occurred on the AAW aircraft during windup turns and loaded reversals at high subsonic flight conditions. The aircraft response to buffet was small and was rarely noticed by the pilot, even though it caused large changes in wing torque loads and trailing-edge surface hinge moments. Wing-bending moments and leading-edge surface hinge moments were only slightly affected by buffet; but the wing-fold torque load was greatly reduced during buffet, causing a nonlinear relationship between the model input parameters and the load. The linear loads model was unable to account for buffet, resulting in large errors at high load. The neural network model predicted the wing-fold torque load during these maneuvers with much lower error. Figure 7 shows a comparison of the linear model prediction and neural network prediction to the measured load during buffet. The maneuver shown is a 1/2-stick, $4 \mathrm{~g}$ loaded reversal. 


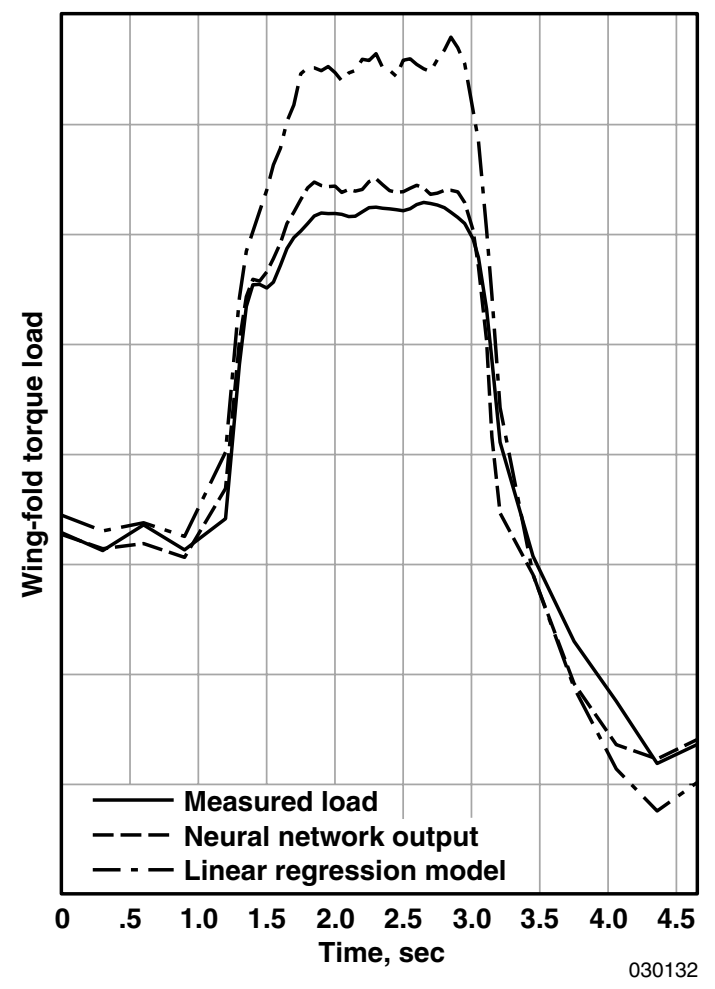

Figure 7. Comparison of linear model, neural network, and measured wing-fold torque load during a 1/2-stick loaded reversal.

Nonlinear surface effectiveness in load was found on all surfaces. On the inboard and outboard leading-edge-flap surfaces, a larger-than-expected free play or dead band was observed. This is demonstrated by comparing the actuator position to surface position measurements taken from string potentiometers attached to the surface at the inboard edge and outboard edge. Figure 8 shows a pitchup-pushover maneuver with a jump in surface position because of free play. Surface flexing is also apparent during the maneuver by the movement of the surface position before and after the jumps. Since actuator free play and flexibility were not modeled in the flight simulator, only the actuator position could be used as input to the loads models. Free play and flexibility presented a modeling problem because the actuator position data do not describe the actual surface position very well. Figure 9 gives a comparison of the linear model prediction and neural network prediction to the measured inboard leading-edge-flap hinge moment for this maneuver. Both models were able to model the load because they use additional inputs, such as angle of attack, in addition to the surface position. Neural network error is lower because of its ability to account for the surface free play. 


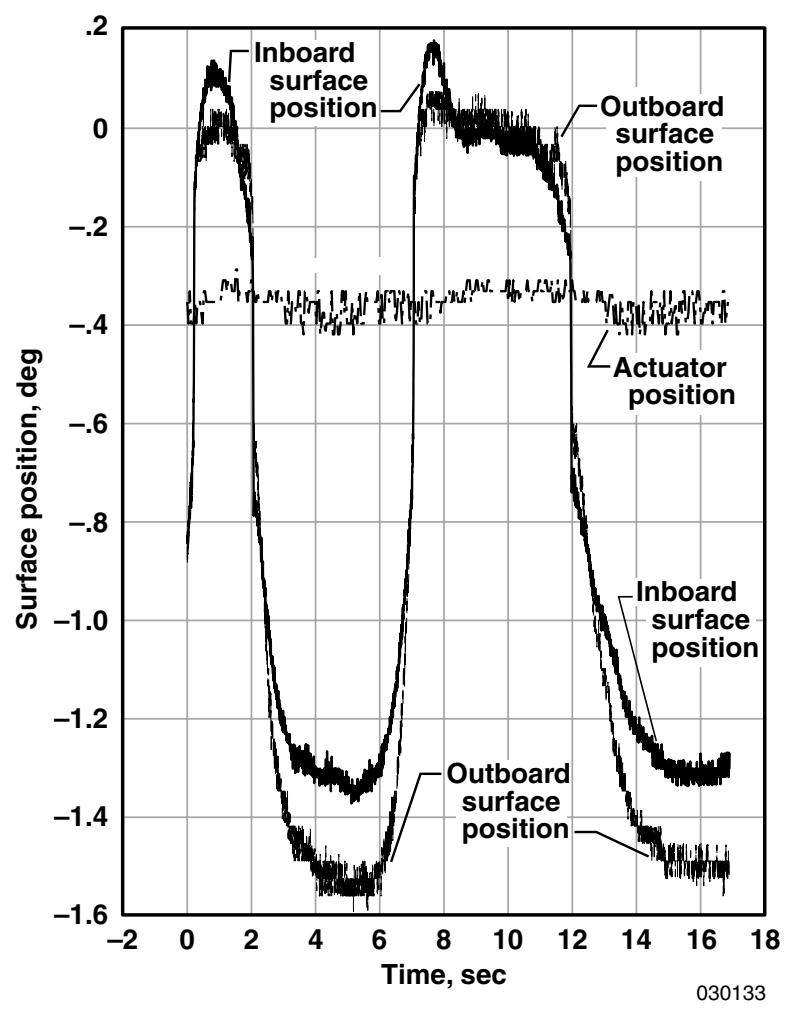

Figure 8. Inboard leading-edge-flap free play and flex during a pitchup-pushover maneuver.

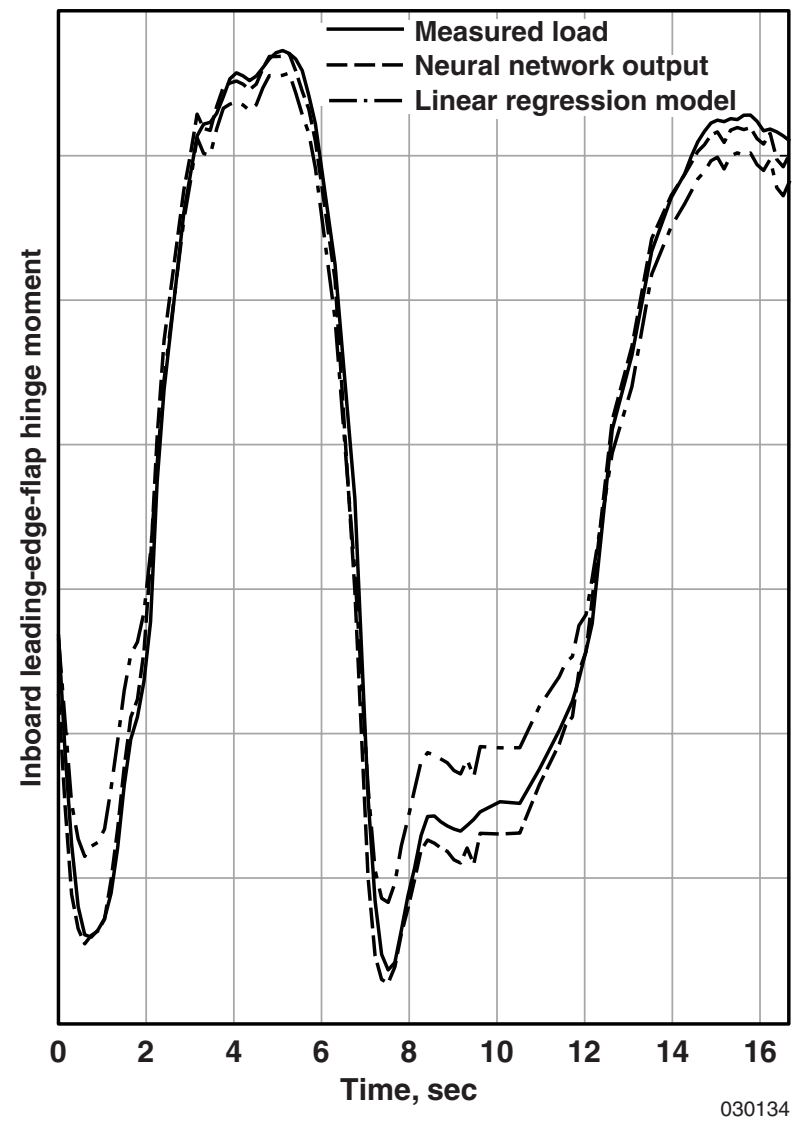

Figure 9. Comparison of linear model, neural network, and measured inboard leading-edge-flap hinge moment during a pitchup-pushover maneuver.

Some nonlinear surface effectiveness in load was found with the trailing-edge flap and aileron surfaces. Figure 10 gives a comparison of the linear model prediction and neural network prediction to the measured inboard trailing-edge-flap hinge moment for a trailing-edge-flap doublet. The linear model is constrained to fit both low-load maneuvers, such as this doublet, and high-load maneuvers, such as rolls, with a single gain on each parameter. The neural network is free to fit nonlinear trends in the data using nodes with the nonlinear function given in equation (2).

A comprehensive summary of results was conducted with all of the validation maneuvers. Table 2 shows the average error and percentage improvement of the neural network for the validation maneuvers for each load. Improvement percentages were based on linear model error. Neural network models have consistently lower errors when compared to linear models. Significant improvements are generally found with loads that have high linear model errors. Large improvements in neural network model error indicate nonlinear relationships between the input variables and the load. Other sources of error such as measurement drift, measurement lag, control surface friction, load hysteresis, changes in flight condition, and wing fastener slop are sources of error for both methods. This summary of model performance shows the benefit of using neural networks to model loads on a fixed wing aircraft at transonic flight conditions. The average error for all loads and all maneuvers was found to be 18.6 percent. 


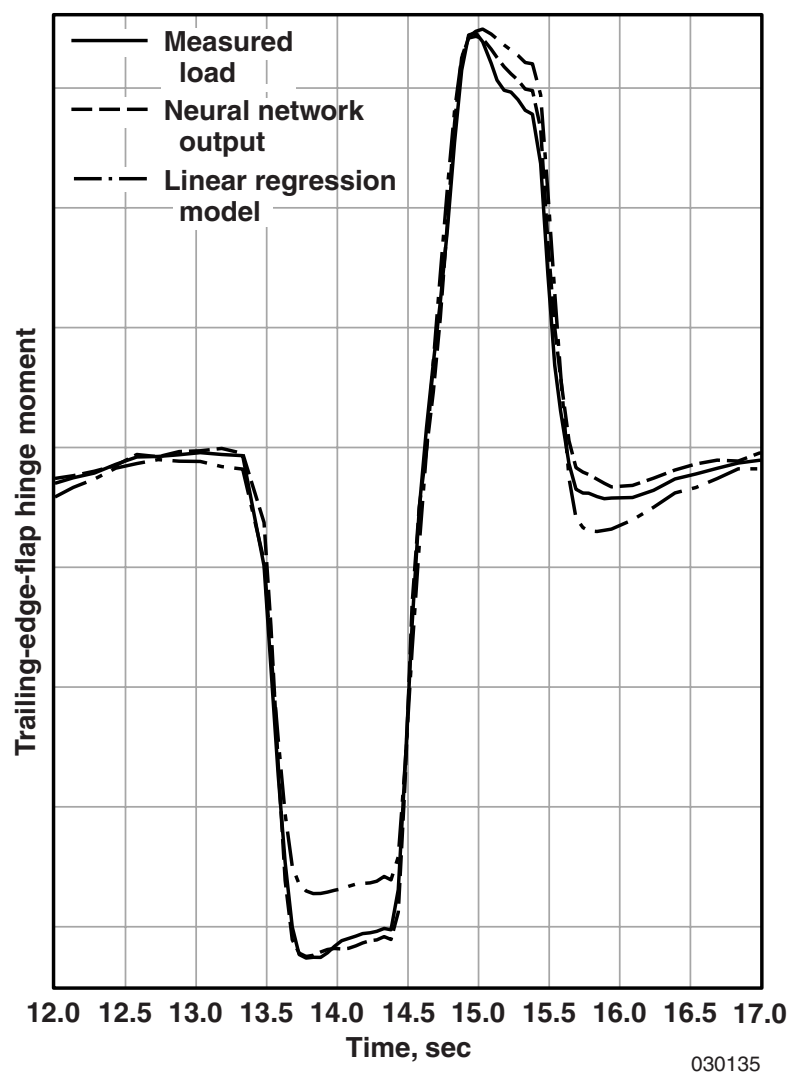

Figure 10. Comparison of linear model, neural network, and measured trailing-edge-flap hinge moment during a trailing-edge-flap doublet.

Table 2. Comparison of neural network and linear model average error from validation files for all loads.

\begin{tabular}{lccc}
\hline \hline \multicolumn{1}{c}{ Load } & $\begin{array}{c}\text { Linear model } \\
\text { error }\end{array}$ & $\begin{array}{c}\text { Neural network } \\
\text { error }\end{array}$ & $\begin{array}{c}\text { Difference, } \\
\text { percent }\end{array}$ \\
\hline Wing-root bending & 1.41 & 1.23 & 12.6 \\
Wing-root torque & 5.31 & 3.20 & 39.5 \\
Wing-fold bending & 1.36 & 1.33 & 2.3 \\
Wing-fold torque & 5.07 & 4.28 & 15.5 \\
Inboard leading-edge-flap hinge moment & 2.53 & 1.95 & 22.8 \\
Outboard leading-edge-flap hinge moment & 6.19 & 4.52 & 26.9 \\
Trailing-edge-flap hinge moment & 3.45 & 2.68 & 22.2 \\
Aileron hinge moment & 5.05 & 4.70 & 6.9 \\
\hline \hline
\end{tabular}




\section{SUMMARY OF RESULTS}

Neural network models were successfully created using Levenberg-Marquardt training with Bayesian regulation to model wing loads for the Active Aeroelastic Wing aircraft. Models were produced for wing-root bending moment and torque loads, wing-fold bending moment and torque loads, and wing-control surface hinge moments at Mach 0.90 and an altitude of 15,000 ft. Linear models produced using linear regression were used for neural network initialization and accuracy comparison. Analysis of the linear and neural network loads models yields the following conclusions.

1. The use of linear regression techniques improved neural network model accuracy by providing a starting point for the neural network.

2. The use of linear regression techniques greatly aided in the selection of model inputs used by the neural network models.

3. Aircraft maneuvers consisting of rolls, loaded reversals, windup turns, and individual surface doublets were adequate for training and evaluating loads models.

4. Single hidden-layer feed-forward neural networks with five to eight nodes were sufficient for modeling loads.

5. Nonlinear trends in the flight data were more accurately modeled with neural networks than with linear regression.

6. Neural network loads models were able to generalize wing loads during validation maneuvers better than linear models, with RMS error improvements ranging from 2-40 percent. Average model improvement was found to be 18.6 percent.

\section{REFERENCES}

1. Abzug, Malcolm J. and E. Eugene Larrabee, Airplane Stability and Control: A History of the Technologies That Made Aviation Possible, Cambridge University Press, New York, NY, 1997.

2. Pendleton, Ed, Denis Bessette, Pete Field, Gerry Miller, and Kenneth Griffin, The Active Aeroelastic Wing Flight Research Program Technical Program \& Model Analytical Development, AIAA-98-1972, 1998.

3. Voracek, David, Ed Pendleton, Eric Reichenbach, Dr. Kenneth Griffin, and Leslie Welch, The Active Aeroelastic Wing Phase I Flight Research Through January 2003, NASA/TM-2003-210741.

4. Chapra, Steven C. and Raymond P. Canale, Numerical Methods for Engineers, McGraw-Hill, 1985.

5. Lewis, George E., “AFTI/F-111 Mission Adaptive Wing Maneuver Load Control," NOTE: ITAR restricted, has number: 1991044498.

6. Olney, Candida D., Heather Hillebrandt, and Eric Y. Reichenbach, An Evaluation Technique for an F/A-18 Aircraft Loads Model Using F/A-18 Systems Research Aircraft Flight Data, NASA/TM-2000-209028. 
7. Haas, David J., Lance Flitter, and Joel Milano, "Helicopter Flight Data Feature Extraction or Component Load Monitoring," Journal of Aircraft, Vol. 33, No. 1, January-February 1996.

8. Haas, David J. and Robin Imber, "Identification of Helicopter Component Loads Using Multiple Regression,” Journal of Aircraft, Vol. 31, No. 4, July-August 1994.

9. Haas, David J., Joel Milano, and Lance Flitter, "Prediction of Helicopter Component Loads Using Neural Networks," Journal of the American Helicopter Society, Vol. 40, No. 1, January 1995.

10. Lokos, William A., Candida D. Olney, Tony Chen, and Natalie D. Crawford, Strain Gage Loads Calibration Testing of the Active Aeroelastic Wing F/A-18 Aircraft, NASA/TM-2002-210726.

11. Hagan, Martin T. and Mohammad B. Menhaj, "Training Feedforward Networks with the Marquardt Algorithm," IEEE Transactions on Neural Networks, Vol. 5, No. 6, November 1994, pp. 989-993.

12. MacKay, David J. C., "Bayesian Interpolation,” Neural Computation, Vol. 4, No. 3, 1992, pp. 415-447.

13. The Mathworks, Inc., "Neural Network Toolbox, Version 4.0," Natick, MA, September 2000, on the Web at www.mathworks.com.

14. Ferrari, Silvia and Robert F. Stengel, "Classical/Neural Synthesis of Nonlinear Control Systems," Journal of Guidance, Control, and Dynamics, Vol. 25, No. 3, May-June 2002, pp. 442-448. 


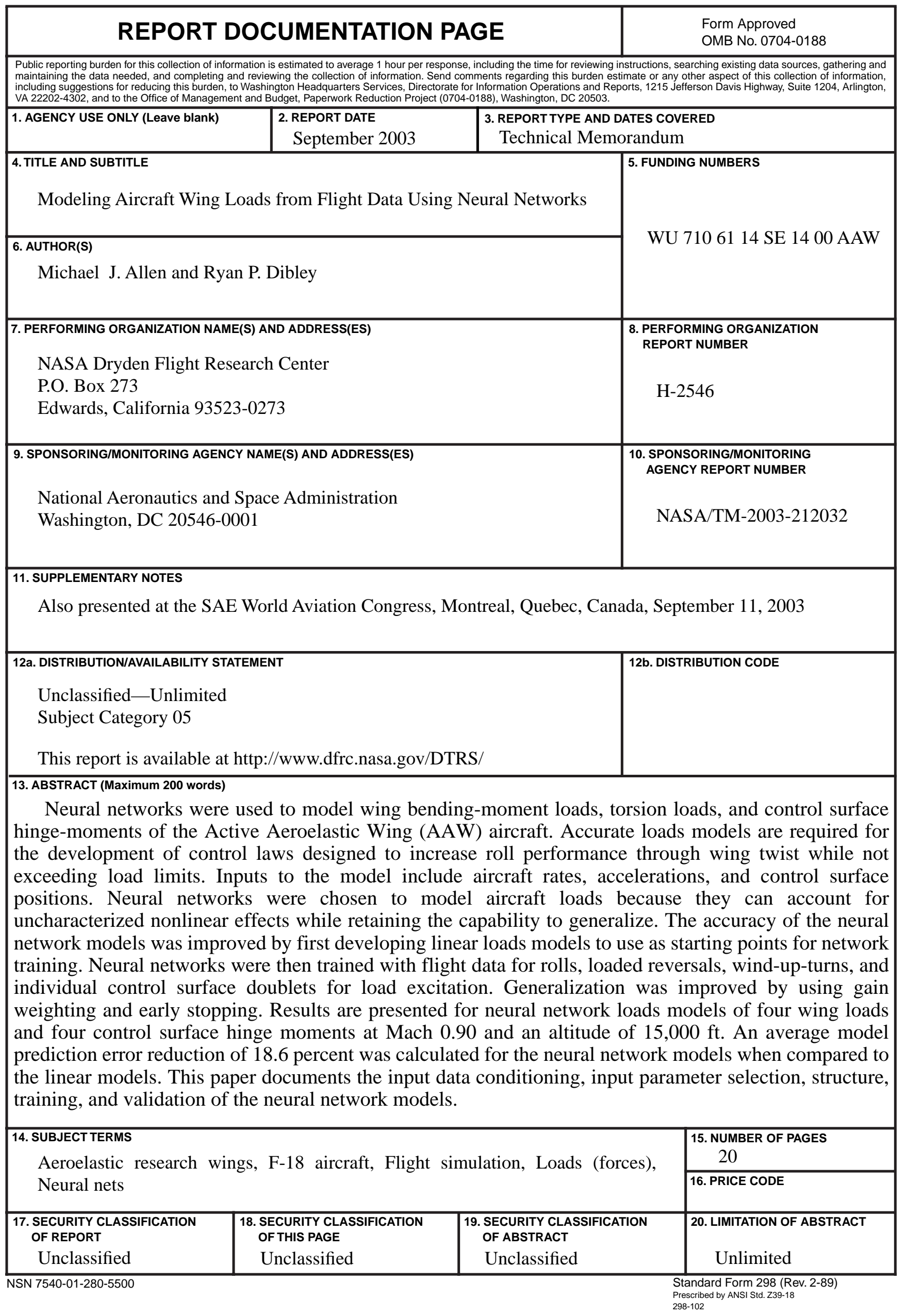

